Original Research Paper

\title{
Application of Titanium Dioxide Self-Cleaning Coatings on Photovoltaic Modules for Soiling Related Losses Reduction
}

\author{
${ }^{1}$ Annalisa Andaloro and ${ }^{2}$ Francesco Frontini \\ ${ }^{I}$ Department of Architecture, \\ Built Environment and Construction Engineering, Politecnico di Milano, Milano, Italy \\ ${ }^{2}$ Institute of Sustainability Applied to the Built Environment, \\ University of Applied Sciences and Arts of Southern Switzerland SUPSI, Canobbio, Switzerland
}

\author{
Article history \\ Received: 13-11-2016 \\ Revised: $16-11-2016$ \\ Accepted: 30-11-2016 \\ Corresponding Author: \\ Annalisa Andaloro \\ Department of Architecture, \\ Built Environment and \\ Construction Engineering, \\ Politecnico di Milano, Milano, \\ Italy \\ Email: annalisa.andaloro@polimi
}

\begin{abstract}
Several studies have assessed the influence of soiling deposition on Photovoltaic (PV) modules front-cover with regards to performance losses over time. In fact, soiling phenomena in PV systems are ascribed as responsible for medium and long-term yield reduction up to $16 \%$ over the first-year of outdoor exposure. Provided that PV technology is a low yield energy production source, maintaining module initial power output declared values is of the outmost importance to ensure that the return time of investment matches project calculations. The scope of this work was a detailed investigation on self-cleaning coating application as a viable retrofit option on already installed modules, or on newly built PV systems, to avoid soiling build-up on front-covers and guarantee threshold performance level in time. The aim is to provide system designers with a consistent alternative to manual cleaning, without losing effectiveness in terms of yield maintenance. The use of self-cleaning coating instead of acting on panels on a regular basis is more convenient in terms of operation and cost. These issues were analyzed through a set of experiments performed both on commercial size modules and laboratory assembled samples. Results prove product compatibility with PV components and its effectiveness in preventing soiling and dust deposition. Outcomes are presented in terms of maximum power output $\left(\mathrm{P}_{\max }\right)$ variation according to measurements performed in Standard Test Conditions (STC) at different time steps. In addition, a parallel comparison with uncoated modules exposed to the same outdoor conditions is also proposed to allow for $\mathrm{P}_{\max }$ variation monitoring performed on a reference sample.
\end{abstract}

Keywords: PV Maintenance, Yield Losses, Soiling, Self-Cleaning, Titanium Dioxide

\section{Introduction}

The accumulation of soiling on the front glass of photovoltaic systems has consistent implications on electrical production levels. As a matter of fact, photovoltaic module power production is proportional to the quantity of incident light reaching the PV cell surface. Dust deposition on transparent surfaces is responsible for optical properties variation, which typically results in reduced light transmittance for module front cover in the case of PV systems (Sarver et al., 2013). For this reason, preventing stable deposition of dust is fundamental to ensure actual performance levels during the PV plant service life are coherent with predicted design values. Other factors playing a role in expected versus effective energy production scattering are: Solar irradiation intensity, air temperature, wind velocity and angle of incidence. However, it is possible to optimize design in order to limit the negative effects of the above. For example choosing the appropriate geographic site and defining the best possible system layout according to boundary conditions can dramatically affect the performance of the PV plant over time. Furthermore, large photovoltaic plants are frequently installed according to climatic features of the specific area, 
preferring geographic zones characterized by high solar irradiation values. These areas would typically belong to arid or semi-arid climates. In such places air is usually rich in suspended dust particles. As briefly mentioned before, their deposition and persistence on module front covers is among the main causes of power production losses during PV system service life.

Several experimental studies (Appels et al., 2013; Kaldellis and Kapsali, 2011; Kaldellis and Kokala, 2010; Kalogirou et al., 2013; Rao et al., 2014; Zang and Wang, 2011) were devoted to exploring and quantifying the effects of dust deposition in term of power production losses for PV systems and single modules. Dust accumulated on PV panels can vary dramatically according to a number of parameters, such as module tilt angle, exposure time period, climate conditions and dust chemical and physical characteristics, such as composition and particle dimension (Lorenz et al., 2013). In addition to this, losses themselves can have different percentages according to the specific PV technology. More specifically, crystalline silicon technologies rely on direct solar irradiation to produce power, while thin film modules ensure acceptable performance levels also under the effect of sole diffused solar radiation. It is easily inferred that this issue has a greater impact in the case of crystalline silicon technologies, whose power production depends exclusively on direct irradiation (Jiang et al., 2011; Kalogirou et al., 2013; Rocha et al., 2008). Literature on the topic of photovoltaic yield reduction due to soiling deposition was reviewed to provide a clearer framework for the topic. Main outcomes of analyzed studies are reported in Table 1. The table is arranged in five columns containing the following data: (1) Type of photovoltaic technology involved in the experiment: Mono or poly-cristalline silicon, amorphous silicon or miscellaneous in the case several types were tested during the same experiment (2) type of test-laboratory or outdoor, shortened in "Lab" or "Out" and its duration in months or days, shortened in "M" or "D"; (3) location where outdoor exposure took place, when applicable; (4) declared losses in percentage of the original nominal module yield; (5) reference paper for further details. It must be noticed that results of those studies are in most cases strongly linked to specific features of the geographic location where experiments were performed.

Numerical models for soiling related losses simulation have been proposed, but parameters affecting this phenomenon are numerous and it is not easy to integrate all of them in a single model (Mekhilef et al., 2012). Dust characteristics and average particle dimensions have been investigated in a number of works, proving that smaller particles can be ascribed as responsible for higher light scattering effects, while larger sand or dust particles are less harmful to PV electrical power production (Beattie et al., 2012). Small particles also tend to coalesce on PV module surface more rapidly than larger ones, being able to cause punctual obstruction on the light capturing surface. Maintaining the front covers of solar active systems in a good state of cleanliness is fundamental to ensure constant performance levels over time. Presently, this is ensured through manual cleaning operations. Despite being not cost effective, this is the most diffused option in the field. In the past, also automatic cleaning mechanisms have been proposed but none of them provided satisfactory results both in terms of cleaning performance and energy required for operation. In this frame, the application of functional coatings that are able to modify surface behavior with respect to dust accumulation on module front cover certainly represent a promising alternative to manual cleaning.

Table 1. Effects of dust deposition intensity on yield losses for different tested PV modules

\begin{tabular}{lllll}
\hline PV technology & Test type/time & Location & Declared losses & Reference \\
\hline Mono-crystalline silicon & Out 12 M & Malaga - Spain & $2-16 \%$ & (Rocha et al., 2008) \\
Mono-crystalline silicon & Out 3 M & Cyprus & $0-14 \%$ & (Kalogirou et al., 2013) \\
Mono-crystalline & Out 2 M & Thailand & $3-5.8 \%$ & (Zang and Wang, 2011) \\
Poly-crystalline silicon & Out 2 M & Athens-Greece & $6.5 \%$ & (Kaldellis and Kokala, 2010) \\
Poly-crystalline silicon & Out 2 M & Athens-Greece & $0-30 \%$ & (Kaldellis and Kapsali, 2011) \\
Poly-crystalline silicon & Out 2 M & Leuven-the Netherlands & $3-4 \%$ & (Appels et al., 2013) \\
Poly-crystalline & Out 1 D & Bangalore-India & $6-8 \%$ & (Rao et al., 2014) \\
Poly-crystalline & Out 2 M & Thailand & $2.8-6 \%$ & (Zang and Wang, 2011) \\
Poly-crystalline silicon & Out 3 M & Cyprus & $0-15 \%$ & (Kalogirou et al., 2013) \\
Amorphous silicon & Out 2 M & Thailand & $3.5-7.3 \%$ & (Zang and Wang, 2011) \\
Amorphous silicon & Out 3 M & Cyprus & $0-9 \%$ & (Kalogirou et al., 2013) \\
Miscellaneous & Out 12 M & California (various) & $13.9 \%$ & (Mejia and Kleissl, 2013) \\
Miscellaneous & Out 12 M & California (various) & $1.5-6.2 \%$ & (Kimber et al., 2007) \\
Mono-crystalline silicon & Lab n.a. & n.a. & $0-22 \%$ & (Jiang et al., 2011) \\
Poly-crystalline silicon & Lab n.a. & n.a. & $0-22 \%$ & (Jiang et al., 2011) \\
Poly-crystalline & Lab n.a. & n.a. & $45-55 \%$ & (Rao et al., 2014) \\
Amorphous silicon & Lab n.a. & n.a. & $0-26 \%$ & (Jiang et al., 2011) \\
\hline
\end{tabular}


In fact, the integration of self-cleaning coatings allows for significant reduction in maintenance costs related to cleaning operations and in the use of water for module washing. This latter has become a globally spread concern and applies especially to arid climates, where most of the largest worldwide PV power plants are located. A variety of functional coatings can be applied to PV modules to meet this objective. They can be mainly divided in two groups according to their behavior with regards to water: Hydrophobic or hydrophilic. In addition to this, surfaces can be functionalized so to perform preliminary decomposition of organic compounds including photocatalytic particles, such as nanocrystalline titanium dioxide in the form of anatase. The work presented in this study is based on the application of a titanium dioxide based self-cleaning coating (Andaloro, 2016; Diamanti et al., 2013) to a variety of samples, with the aim of providing quantitative information on the reduction of soiling related losses for the performed set of experiments. It provides new insights in the field of PV system maintenance operations and aims at spreading awareness on the topic of alternative and more sustainable cleaning strategies to ensure electrical power production levels of PV systems exposed to polluted or dust rich environments.

\section{Experimental and results}

\section{Introduction to Materials and Methods}

All of the experiments described in this section aimed at verifying the expected positive impact of self-cleaning coating application on photovoltaic systems. More specifically, the product under investigation is a sol-gel semitransparent water based solution containing titanium dioxide nanoparticles in the anatase form, referred to as Sol $\mathrm{T}$ in the text. Nanoparticles dispersed in the sol-gel vary in size between few and 20 or $30 \mathrm{~nm}$ (Fig. 1). The suggested deposition thickness is in the order of magnitude of $100 \mathrm{~nm}$ to ensure film transparency even on glass or other translucent substrates. Its use is recommended to provide self-cleaning properties to surfaces, based on the combination of photocatalytic and hydrophilic behavior triggered by solar irradiation. More in detail, the presence of titanium dioxide nanoparticles allows for soiling preliminary decomposition on the surface, through a redox reaction that is easily initiated under the effect of sunlight benefitting from the reduced energy gap of titanium dioxide. Furthermore, the water contact angle of irradiated surface develops quickly to below $10^{\circ}$ and sometimes even closer to $0^{\circ}$ according to the exposure period length. The combination of this two mechanisms creates the so called self-cleaning function, that is to say the surface is easily cleaned under pouring rain-or water-without requiring any additional manual operation.

As a matter of fact, water film forming on coated areas is able to lift and remove soiling deposits that have been previously reduced thanks to the photocatalytic properties. It is important to notice that mechanical stress and abrasion can easily damage the coating photoactive behavior, due to its extremely reduced deposited thickness, as seen in Fig. 1. For this reason, Sol T should rather be applied at the end of manufacturing processes in the case of newly born PV plants. Despite this criticality, its ease of application, usually carried out with compressed air spray, makes this product also suitable for retrofit actions. Performance monitoring of self-cleaning coatings is necessarily carried out through indirect methods, as there is no unambiguous parameter that can represent self-cleaning efficiency to be measured through the use of a specific instrument. Relevant parameters vary according to the kind of substrate involved, spanning from colorimetric tests in the case of opaque reflective materials to optical properties or electrical power output variation. More in detail, measurements performed in this study rely on the decrease of transmittance as an index of soiling depositing on the surface. This method is based on the fact that light hitting a translucent surface can be either reflected, absorbed or transmitted. Provided that material properties are not subject to relevant physical modifications during the monitoring period, decreased light transmittance demonstrates that particles deposited on a surface are either absorbing or reflecting part of the incident light. Furthermore, soiling of photovoltaic modules included in this study is determined through the decrease in electrical power production as a result of light transmittance losses related to front glass.

\section{Commercial PV modules - experimental results}

Two standard commercial PV modules were employed for this experiment, whose technical specifications are provided in Table 2. Both modules were coated with sol $\mathrm{T}$ and subjected to accelerated weathering in a controlled environment chamber according to the 61215 IEC: 2005 standard, before being exposed in the open field. This operation had the aim of simulating the effect of coating application on PV modules and verify that the self-cleaning effect was not reduced by thermal stress induced during the cycles.

Table 2. Photovoltaic modules characteristics

\begin{tabular}{llllll}
\hline Name & Producer & Type & Pmax (STC) & Fill factor & Thermal cycles \\
\hline A-1 & Sharp & m-Si & $172.68 \mathrm{~W}$ & 71.50 & 2 \\
A-4 & IBC & m-Si & $208.16 \mathrm{~W}$ & 74.94 & 1 \\
\hline
\end{tabular}




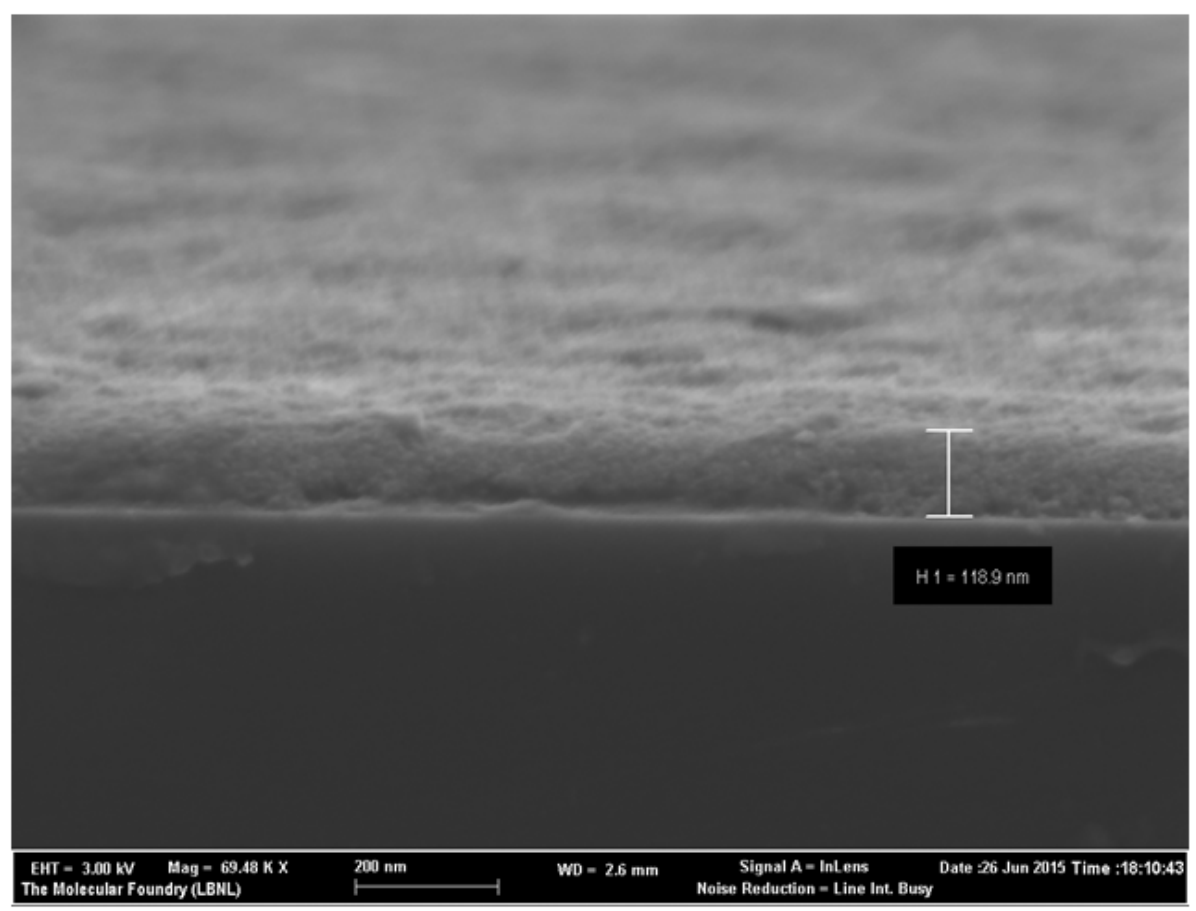

Fig. 1. Cross section view showing average film thickness on a silicon wafer (source: courtesy of The Molecular Foundry at Lawrence Berkeley National Laboratory (California, USA))

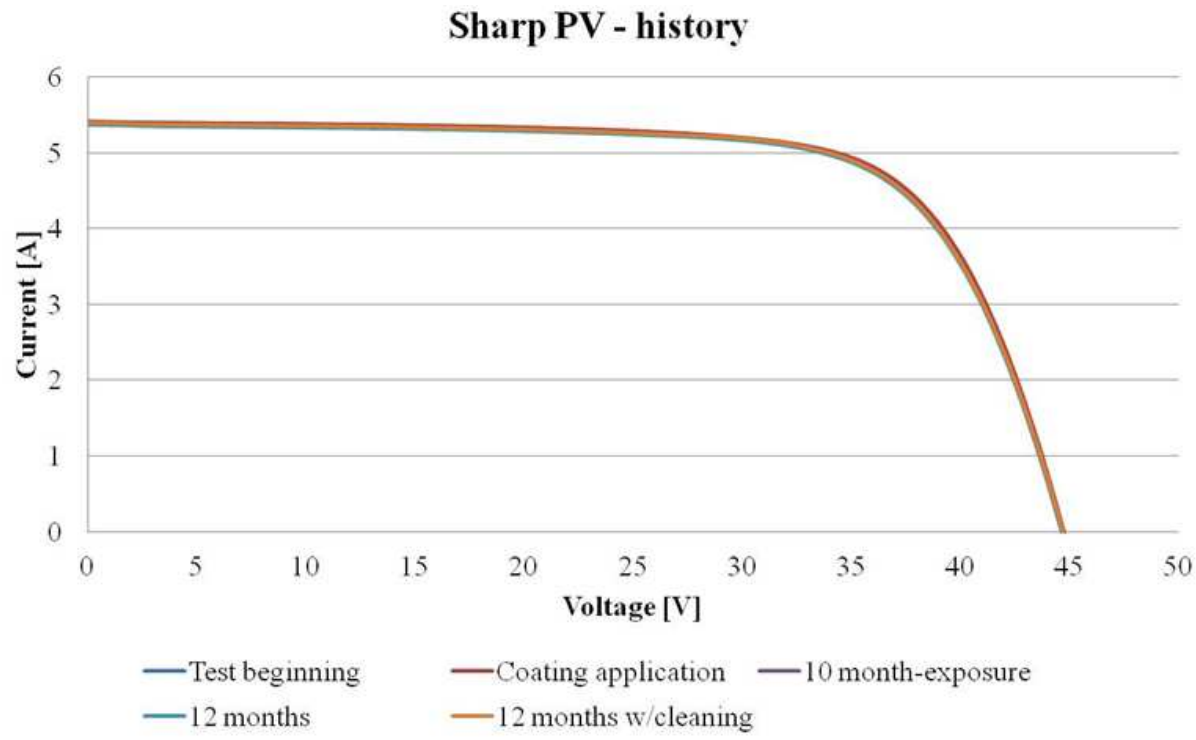

Fig. 2. I-V curves for 14-I09-A-1 module, manufactured by Sharp. After the 10 month-exposure, very little difference was reported. This module was exposed to accelerated thermal cycles before being exposed outdoor

Maximum power output (Pmax) in Standard Test Conditions (STC) was measured for both samples before test beginning (Table 1) and immediately after coating application, proving no decrease in power production was encountered due to the presence of dispersed titanium dioxide particles on front cover surface.
Modules were located outdoors and their electrical yield has been recorded through a maximum power point tracker type MPPT3000 (MPPT3000 http://www.supsi.ch/isaac/fotovoltaico/sistemi_pv/pro dotti/mppt-3000.html. Accessed on October 30th, 2016) developed by SUPSI for 10 months. Power output measurements in STC were repeated for both 
modules and coupled with electroluminescence pictures, to verify the cells were not being affected by malfunctioning. Data were collected after 10 and 12 months from test beginning, as seen in Fig. 2 and 3.

Measurements are summarized in Table 3 and showed that the self-cleaning coating applied to module front covers helped in maintaining the maximum power output during the monitoring period.

Power losses registered by the two tested modules at the end of the experiment are equal to $1 \mathrm{~W}$, which authors reckon to be more than acceptable after one entire year of outdoor exposure. This result is very promising, as one year exposure is usually a relevant period to observe the first significant power losses, as proved by several studies in the field (Dorobantu et al., 2011; Sayyah et al., 2014; Zorrilla-Casanova et al., 2011)

In addition to the monitoring of modules treated with self-cleaning coatings, a reference module that was installed in the same site and had been exposed for over
3 years-without any manual cleaning being performed during this period-was measured as it was and then thoroughly washed to evaluate soiling related losses for the specific case.

The two curves are presented in Fig. 4. Conversely to what happened in the case of the two coated modules, the soiled and cleaned I-V curves look significantly different from each other and the variation of maximum power output measured in standard text conditions is equal to $5.3 \mathrm{~W}$, determining an average loss equal to $1.8 \mathrm{~W}$ for each year. Of course, soiling build-up on the surface cannot be considered constant, but still this difference is extremely encouraging as coated modules registered almost no losses after the first year of exposure. One of the modules showed higher losses than the other, but this may also be due to other causes that are independent from soiling, such as electrical malfunctioning due to cell damage, as shown in the electroluminescence test.

IBC PV module - history

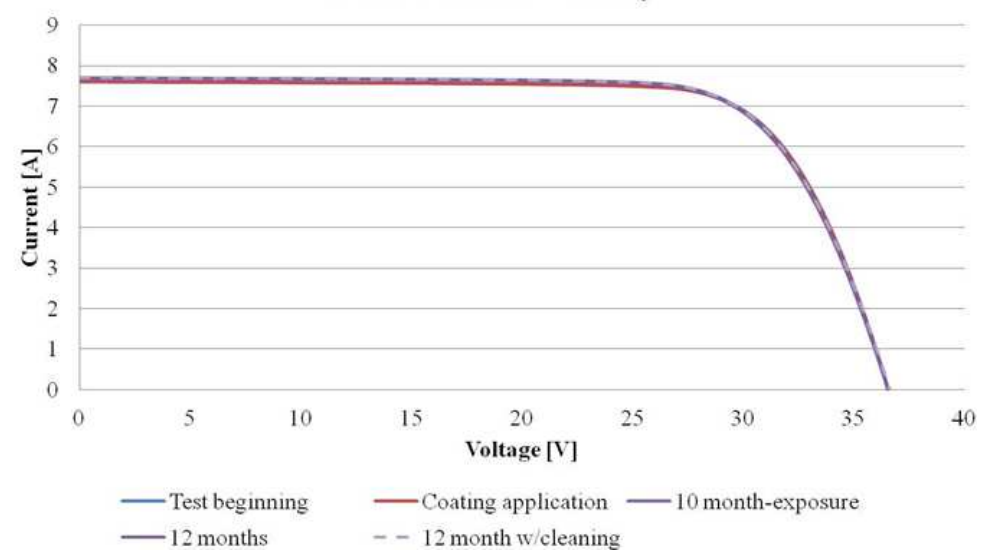

Fig. 3. I-V curves for 14-I09-A-4 module, manufactured by IBC. After the 10 month-exposure, very little difference was reported

Uncoated commercial module

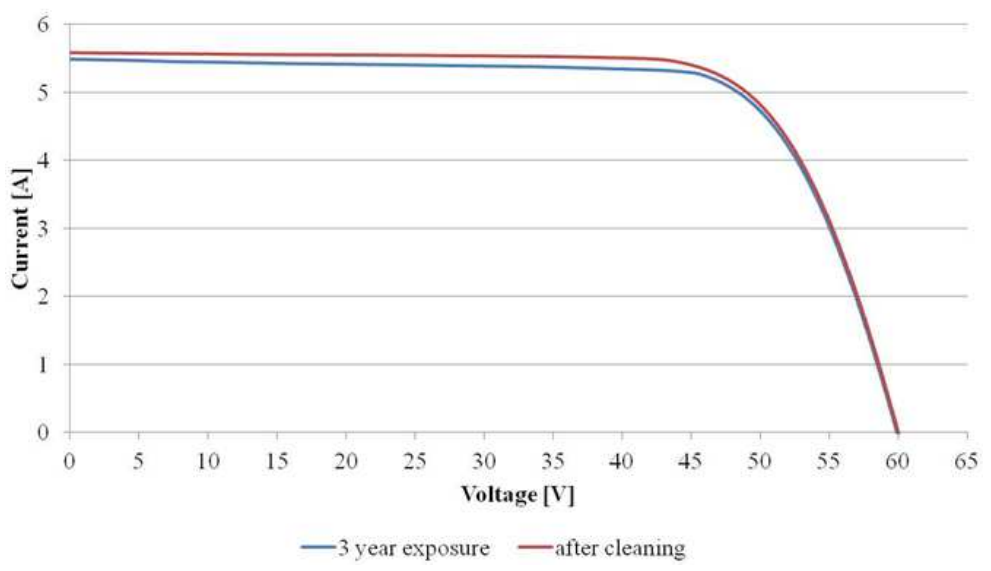

Fig. 4. I-V curves for a standard commercial module. This module was not treated with self-cleaning coatings and exposed to the same outdoor environment as the coated modules 


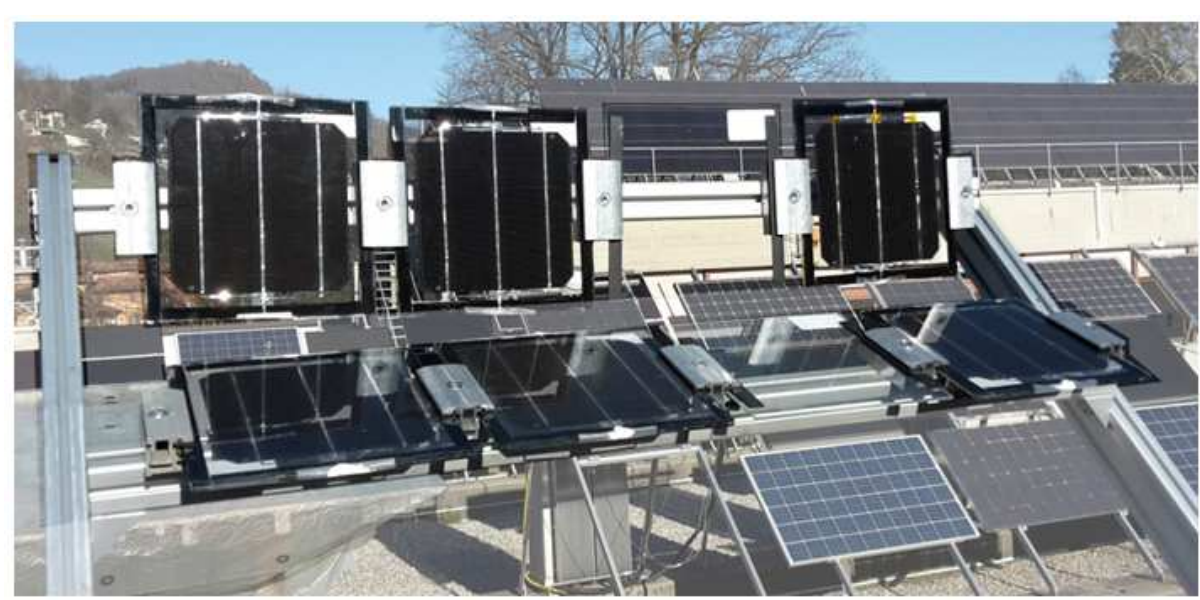

Fig. 5. Test stand for the single cell PV samples and reference glass sample

Table 3. History of maximum power output for the two tested modules.

\begin{tabular}{llll}
\hline Sample name & Time & Max power output STC & Variation with previous \\
\hline A-1 & 0 & $173.2 \mathrm{~W}$ & - \\
& $10 \mathrm{~m}$ & $171.8 \mathrm{~W}$ & $-1.4 \mathrm{~W}$ \\
cleaning & $12 \mathrm{~m}$ & $171.1 \mathrm{~W}$ & $-0.7 \mathrm{~W}$ \\
A-4 & $12 \mathrm{~m}$ & $171.9 \mathrm{~W}$ & $+0.8 \mathrm{~W}(-1.3 \mathrm{~W}$ start-end) \\
& 0 & $208.2 \mathrm{~W}$ & - \\
cleaning & $10 \mathrm{~m}$ & $208.3 \mathrm{~W}$ & $+0.1 \mathrm{~W}$ \\
\hline
\end{tabular}

Table 4. Sample type specifications and exposure tilt angle for tested PV modules and glass samples

\begin{tabular}{llll}
\hline Sample name & Type & Sol T coating & Tilt angle \\
\hline PV 01 & PV module & No & $0^{\circ}$ \\
PV 02 & PV module & Yes & $0^{\circ}$ \\
PV 03 & PV module & No & $90^{\circ}$ \\
PV 04 & PV module & No & $0^{\circ}$ \\
PV 05 & PV module & Yes & $20^{\circ}$ \\
PV 06 & PV module & No & $30^{\circ}$ \\
PV 07 & PV module & No & $20^{\circ}$ \\
PV 08 & PV module & Yes & $30^{\circ}$ \\
PV 09 & PV module & Yes & $90^{\circ}$ \\
PV 10 & PV module & No & $30^{\circ}$ \\
PV 11 & PV module & No & $90^{\circ}$ \\
PV 12 & PV module & Yes & $20^{\circ}$ \\
V 01 & Glass sample & Yes & $20^{\circ}$ \\
V 04 & Glass sample & Yes & $30^{\circ}$ \\
V 09 & Glass sample & Yes & $90^{\circ}$ \\
V 10 & Glass sample & & $0^{\circ}$ \\
\hline
\end{tabular}

\section{Customized PV Modules and Glass Samples- Experimental Results}

Test were also performed on tailor made PV modules assembled on purpose for this study at the BIPV test center of SUPSI. 12 single cell PV modules were laminated using mono-crystalline silicon cells manufactured by $\mathrm{BOSCH}$. Some of these modules were coated using the titaniumdioxide sol-gel applied through compressed air spray and all samples were exposed outdoors according to four tilt angles: Horizontal, vertical, $20^{\circ}$ and $30^{\circ}$ during eleven months, as shown in Fig. 5. In addition, four coated glass samples were exposed in the same location and light transmittance was recorded at the same time intervals. Measurement of maximum power output was performed at the beginning of the test, after 2 months, 5 months, 8 months and at the end of test. Manual cleaning operations were recorded to allow for more precise comparison of results. Details on sample exposure and coating application are provided in Table 4. 
The measurements reported in this section of the paper were made at different time steps during 11-month outdoor exposure with the aim to investigate soiling related losses.

More in detail, monitoring measurements were scheduled as follows: (a) Step 1 was performed at the beginning of the experimental campaign; (b) Step 2 was recorded after 2 months; (c) Step 3 was recorded after 5 months; (d) Step 4 was recorded after 8 months and (e) Step 5 was recorded after 11 months. Manual cleaning operations were also registered and measurements on cleaned modules are reported in the graphs with the same order number-plus cleaning. Not all samples were cleaned the same number of times, as shown in the graphs. This choice was made by authors to provide different evidence of cleaning operations performed at various time steps and on varied tilt angle exposure.

I-V curves for all tested samples are reported in the following and some comments on the achieved results are presented. For ease of graph understanding, intermediate measurements are not reported.

As a general consideration, it is easily noticed that none of the samples has recovered the original I-V curve values even after cleaning. However, this is ascribed to the lack of cell pre-conditioning due to project time constraints.

Samples PV 01-02-04 were placed horizontally on the sample holder. This set of samples showed similar evolution of the characteristics throughout the exposure period. However, sample PV 02 was coated with Sol T and showed minor $I_{s c}$ value decrease compared to the other two samples in the same row. Figure 6a-c shows a comparison between the original I-V curve and values measured at the end of the experimental campaign. The difference between a self-cleaning coated module and uncoated samples is quite evident as I-V curves for the coated module present almost no difference between test start-end, while the effect of manual cleaning is more clearly perceived for uncoated modules. Samples PV 03-09-11 were placed vertically on the sample holder and related I-V curves are reported in Fig. 7. Within this set of samples, sample PV 03 had been cleaned after the first outdoor measurement, while PV 09 was coated with sol T. The characteristic curves of these two samples show similar shapes, despite the coated sample shows slower soiling process. In fact, a comparison among all the three in the same row shows that sample PV 09 has a lower decrease in the maximum power point compared with the other two samples. PV 03 certainly benefitted from the intermediate cleaning performed after the first measurement. However, all the three modules did not register significant decrease in maximum power output and characteristic curves are quite stable, accounting for the stabilization period due to the lack of preconditioning. Of course, this behavior can be ascribed to the favorable effect of vertical inclination that prevents dust deposition and accumulation thanks to the effect of gravity force, in addition to easy washing of the surface under rain showers.

Samples PV 05-07-12 (Fig. 8) were exposed at a $20^{\circ}$ angle with respect to the horizontal plan and showed some differences in soiling behavior after the first 5 months of exposure. Within this set of samples, PV 12 had been cleaned after the first outdoor measurement (2-month exposure), while PV 05 was coated with sol T. The characteristic curves of the coated sample remained almost equal all along the monitoring period. This is encouraging as the application of the coating seems to be a reliable means to maintain front glass transmittance constant over time. The sample with intermediate cleaning also showed non-significant changes in the I-V curve measured after 5 months of outdoor exposure, that is to say 3 months after the cleaning. This result leads to infer that a reasonable cleaning schedule to maintain the nominal power output of a PV power plant in this specific context of exposure could vary between 2 and 3 months.

Samples PV 06-08-10 were exposed at a $30^{\circ}$ angle with respect to the horizontal plan and showed similar differences as in the case of the $20^{\circ}$ tilted samples. Within this set of samples, PV 10 had been cleaned after the first outdoor measurement (2-month exposure), while PV 08 was coated with sol T. Coating efficiency is demonstrated by the fact that soiled and cleaned measurement taken after 5 months of outdoor exposure showed almost no difference. This trend was maintained until the end of the monitoring period, as shown in Fig. 9. This positive anti-soiling behavior is ascribed to selfcleaning coating that minimizes dust adhesion on the module, triggers decomposition of organic pollutant compounds and allows for surface self-washing under the effect of rain. As far as the intermediate cleaning action for sample PV 10 is concerned, its effects are comparable to the previous case.

In fact, cleaning performed after 2 months allowed the characteristic curve to come closer to the original value and report minor losses at the time of the second measurements, 3 months after the first one. Sample PV 06, which had not been previously cleaned, showed the highest $I_{s c}$ decrease among this set of samples at the time of the last measurement, as shown in the corresponding graph. Again, cleaning caused a beneficial effect on the module.

As a general consideration, authors want to point out that all PV samples increased their maximum power point after cleaning operations, as a direct consequence of front glass increased light transmittance. This hypothesis was further proved by transmittance measurements recorded on glass samples from V01 to V04, which were exposed outdoors according to the same tilt angles (Fig. 10-13) 


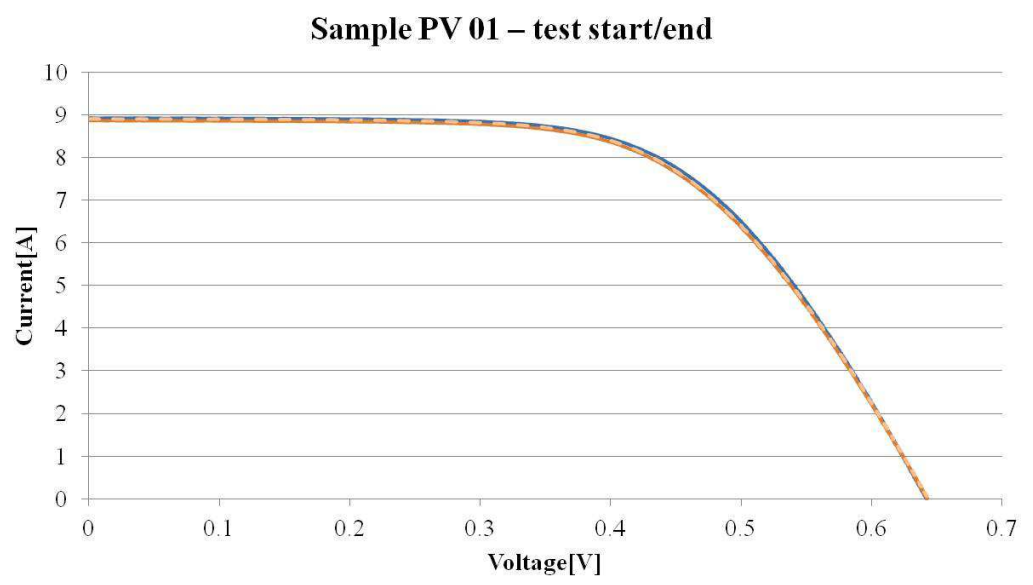

-Step 1 -Step $5=-$ Step 5 w/cleaning

(a)

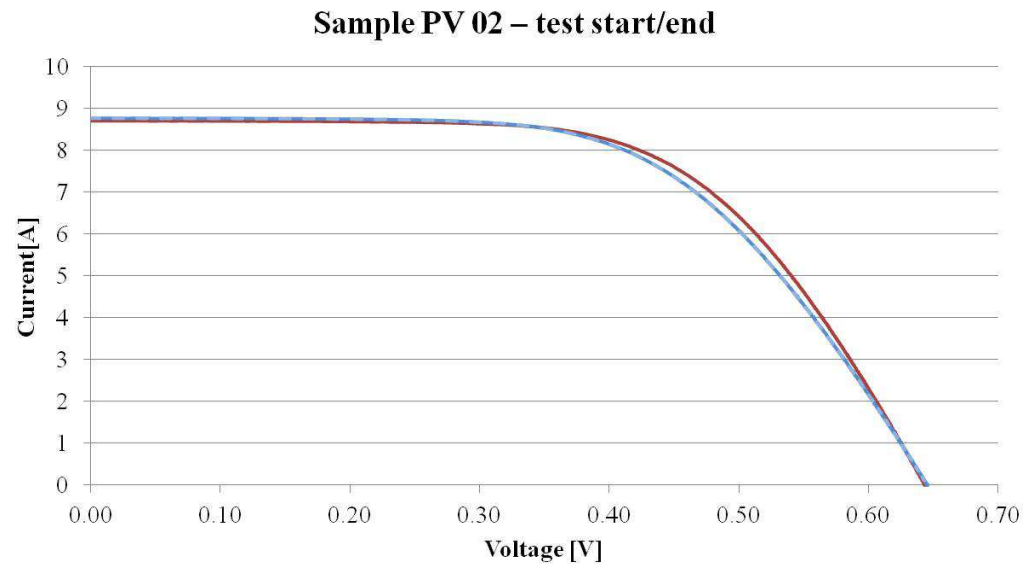

-Step $1 \mathrm{w} /$ coating $\longrightarrow$ Step $5-$ Step $5 \mathrm{w} /$ cleaning

(b)

Sample PV 04 - test start/end

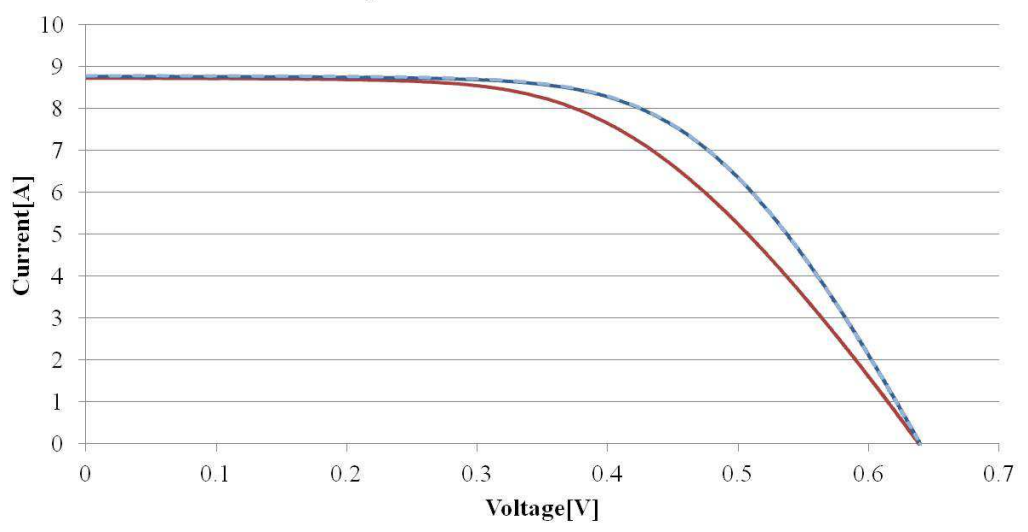

- Step 1 Step 5 - Step 5 w/cleaning

(c)

Fig. 6. a-b-c comparison between I-V curves measured in STC at the beginning of the test and after 11 months, soiled and cleaned (a) sample PV01 (b) sample PV02 (c) sample PV04 


\section{Sample PV 03 - test start/end}

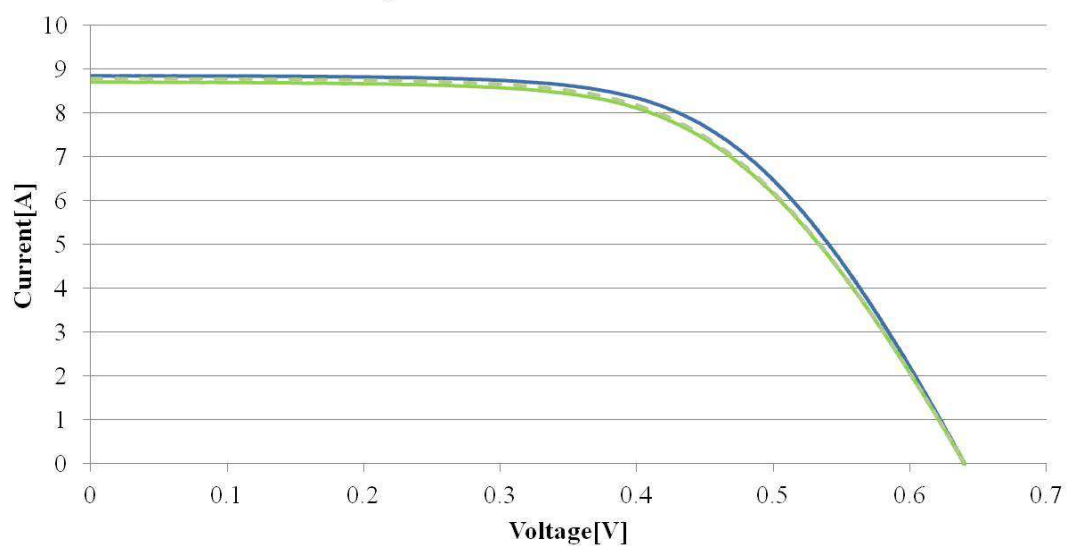

- Step $1-$ Step $5--$ Step 5 w/cleaning

(a)

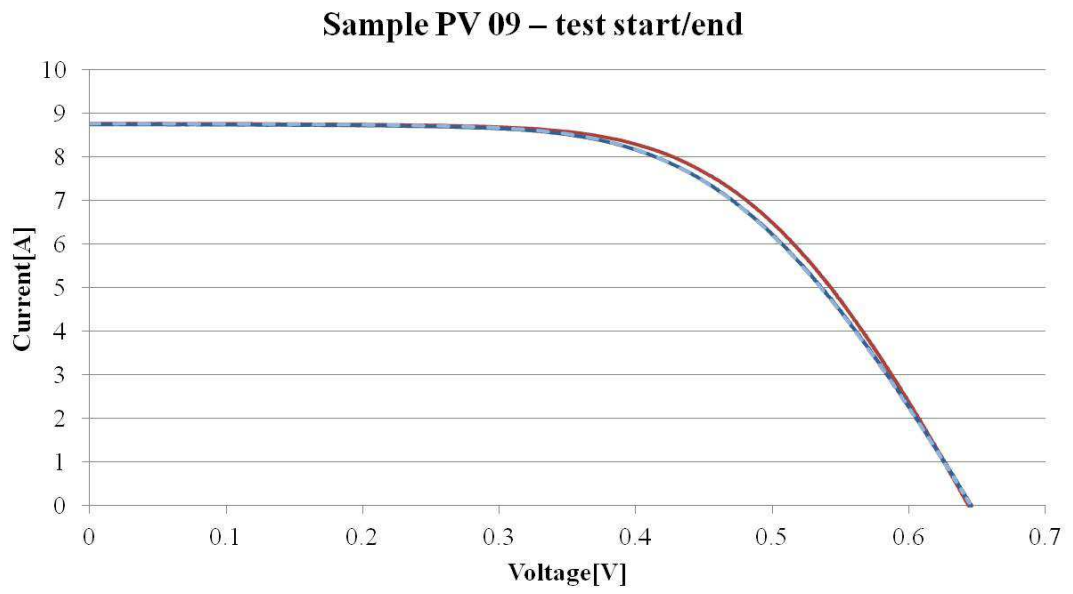

- Step $1 \mathrm{w} /$ coating —Step $5-$ Step $5 \mathrm{w} /$ cleaning

(b)

Sample PV 11 - test start/end

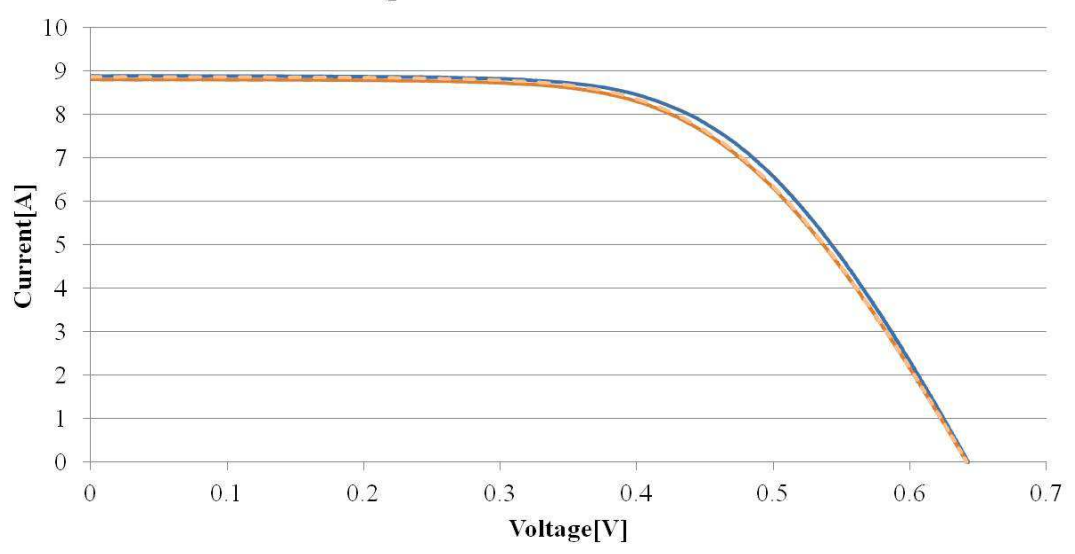

-Step 1 -Step $5-$ Step $5 \mathrm{w} /$ cleaning

(c)

Fig. 7. a-b-c comparison between I-V curves measured in STC at the beginning of the test and after 11 months, soiled and cleaned (a) sample PV03 (b) sample PV09 (c) sample PV11 


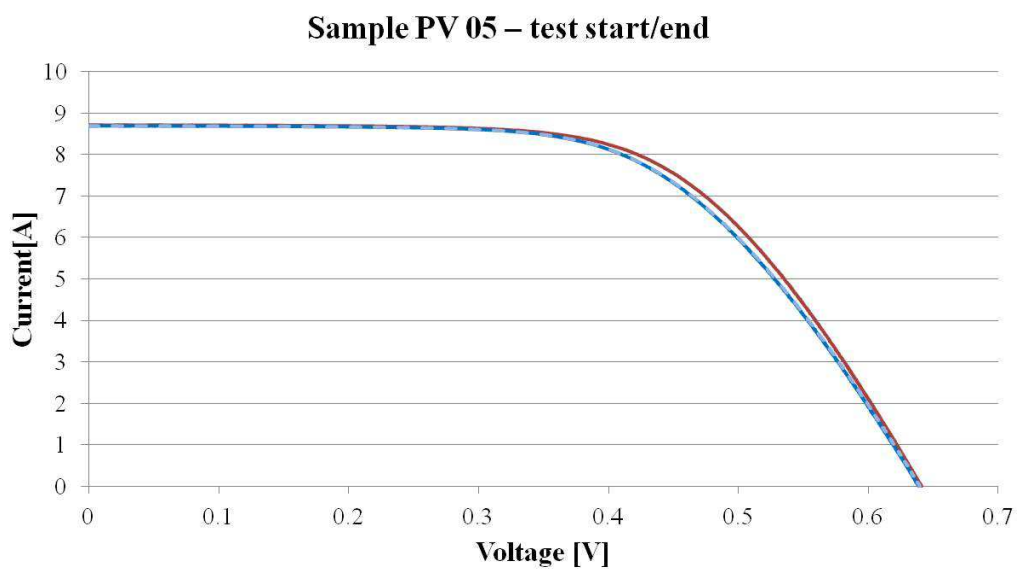

- Step $1 \mathrm{w} /$ coating $\longrightarrow$ Step $5--$ Step $5 \mathrm{w} /$ cleaning

(a)

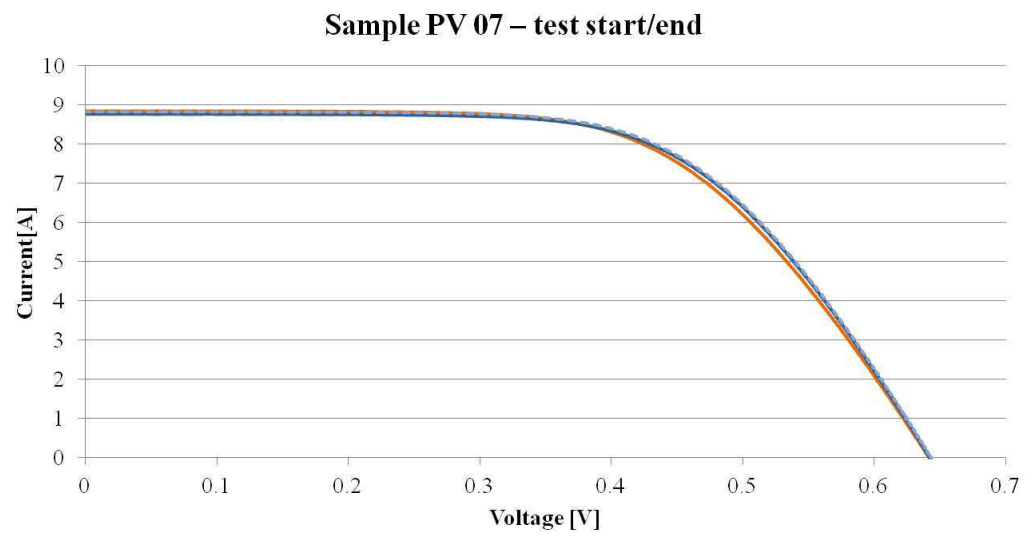

- Step 1 -Step 5 - Step 5 w/cleaning

(b)

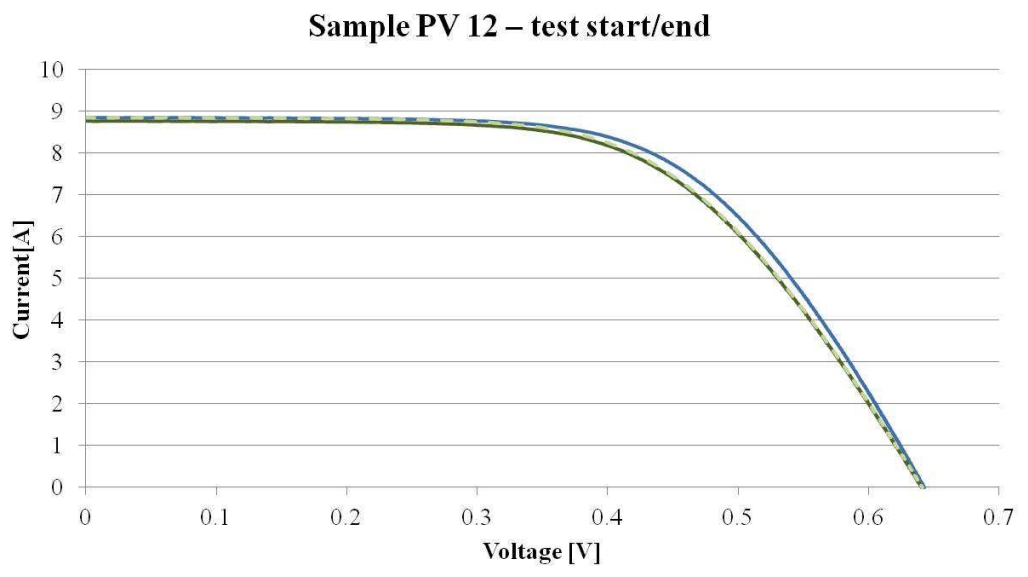

- Step 1 Step $5--$ Step 5 w/cleaning

(c)

Fig. 8. a-b-c comparison between I-V curves measured in STC at the beginning of the test and after 11 months, curve recorded for both soiled and cleaned sample (a) sample PV05 (b) sample PV07 (c) sample PV12 


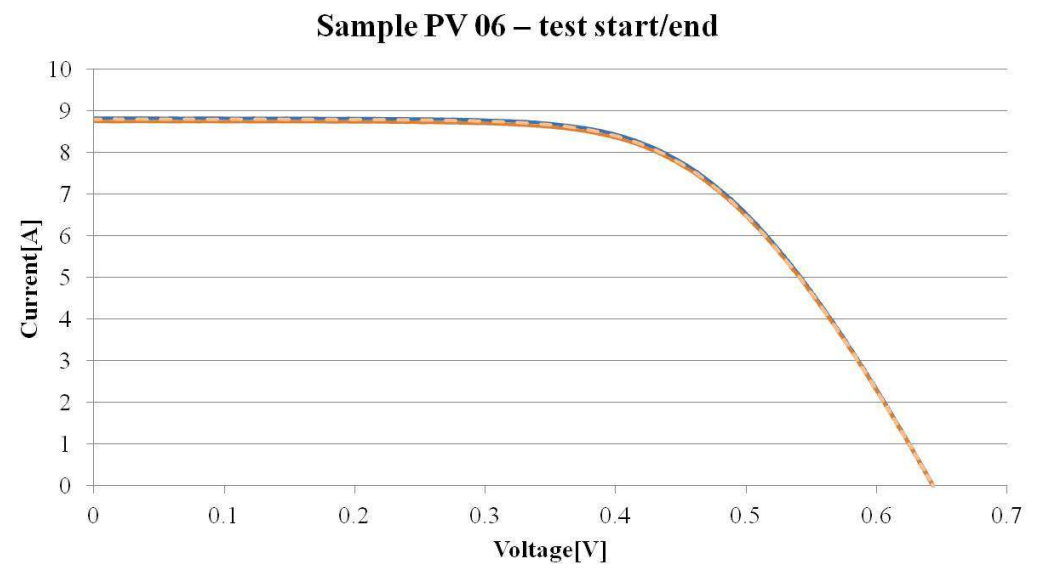

- Step $1 \longrightarrow$ Step $5--$ Step 5 w/cleaning

(a)

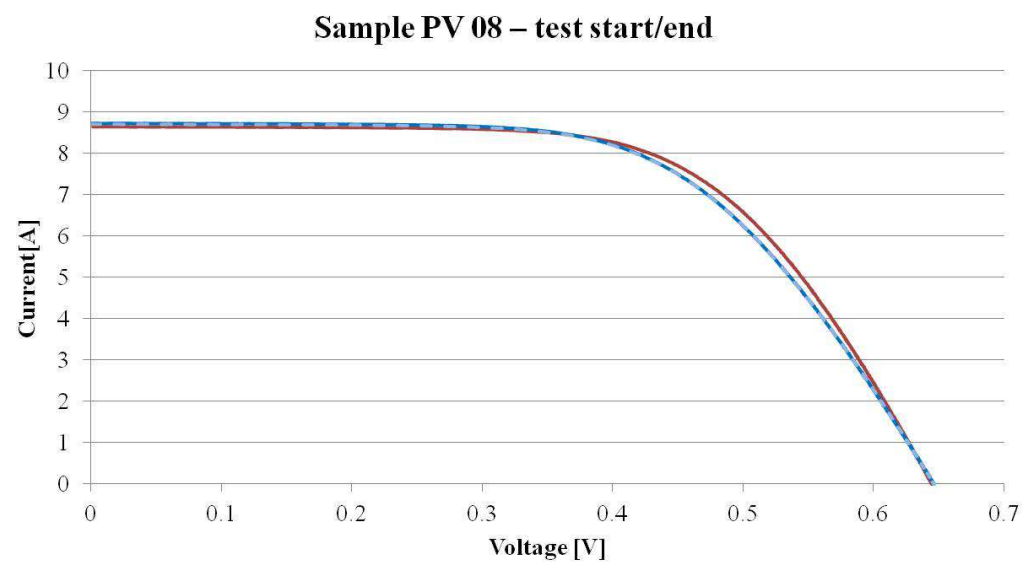

- Step $1 \mathrm{w} /$ coating - Step 5 - Step $5 \mathrm{w} /$ cleaning

(b)

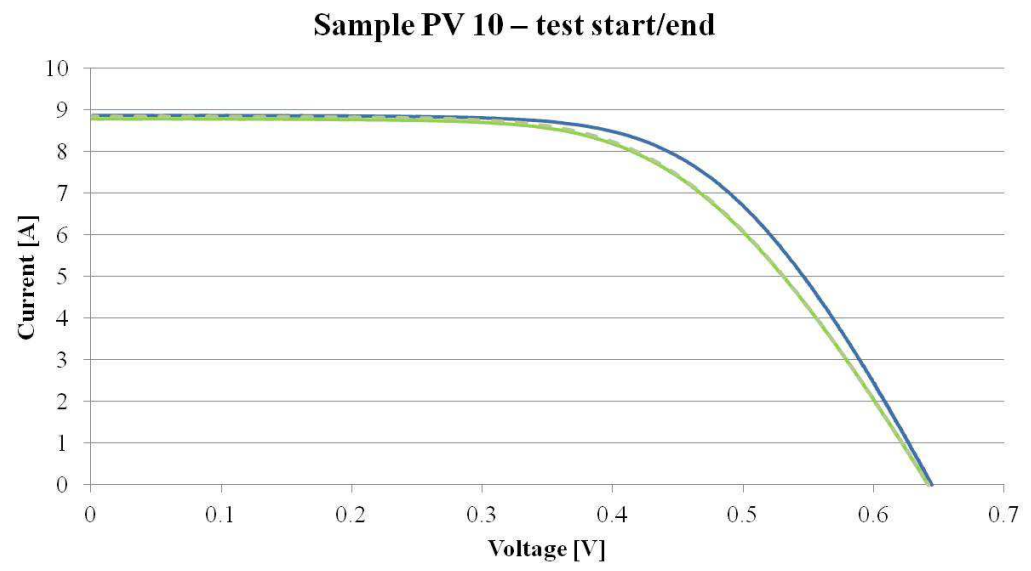

- Step $1-$ Step $5--$ Step 5 w/cleaning

(c)

Fig. 9. a-b-c comparison between I-V curves measured in STC at the beginning of the test and after 11 months, soiled and cleaned (a) sample PV06 (b) sample PV08 (c) sample PV10 
Transmittance History sample V01

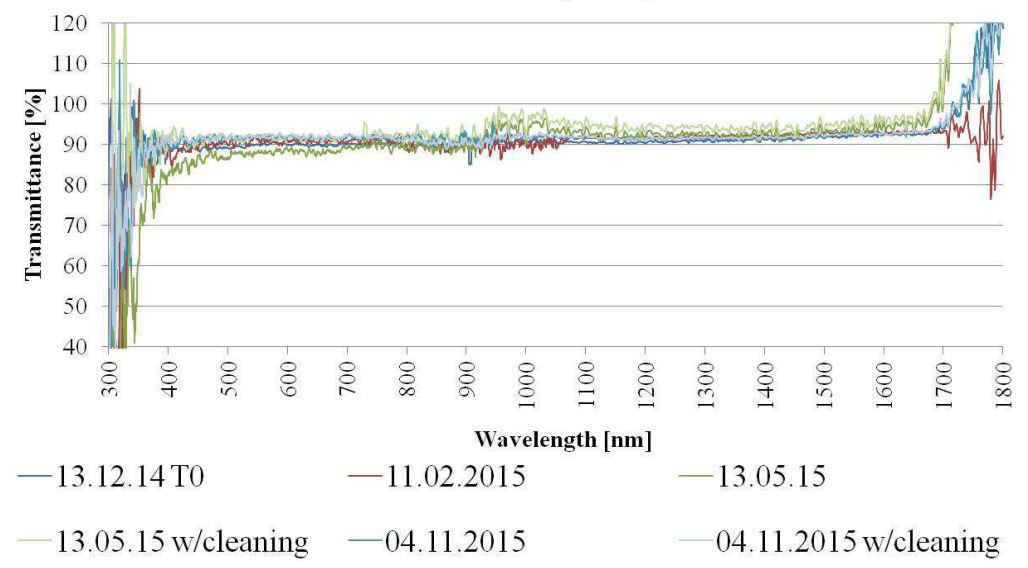

Fig. 10. Light transmittance monitoring of sample V01. Cleaning of the surface was carried out after the first 5 months of outdoor exposure and at the end of exposure

Transmittance History sample V04

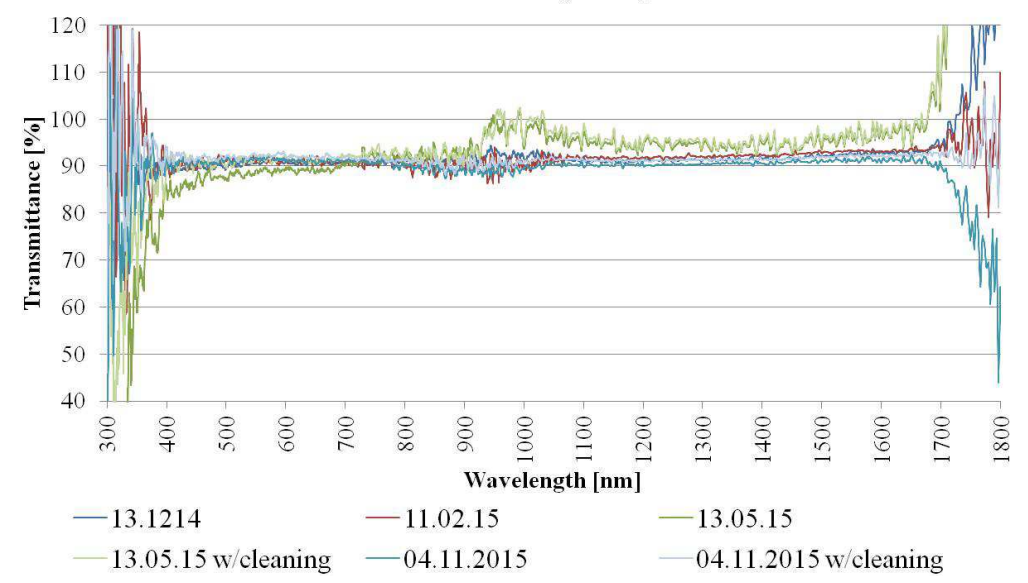

Fig. 11. Light transmittance monitoring of sample V04. Cleaning of the surface was carried out after the first 5 months of outdoor exposure and at the end of exposure

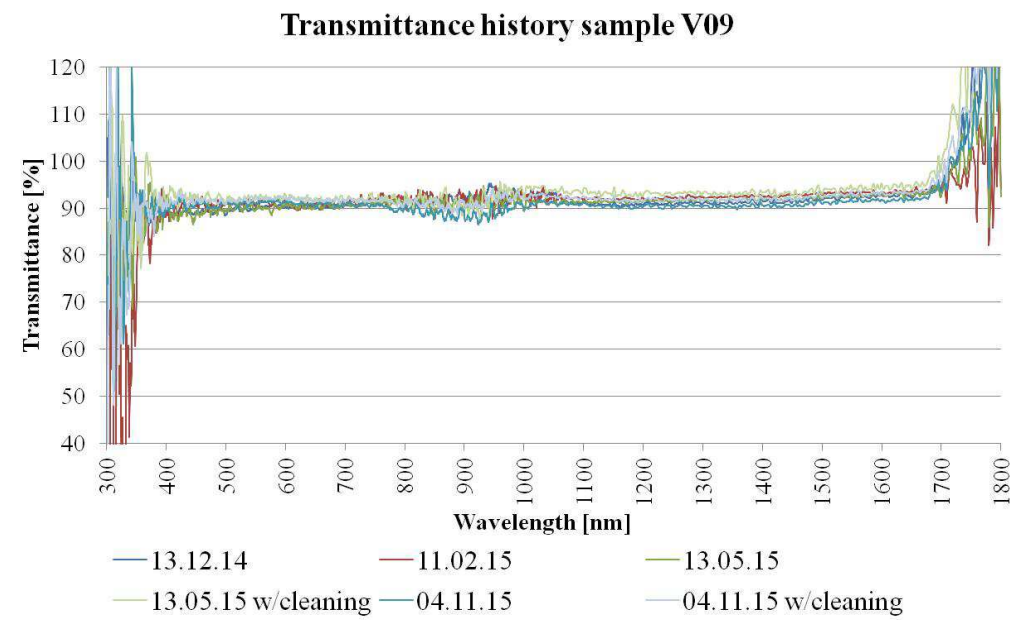

Fig. 12. Light transmittance monitoring of sample V09. Cleaning of the surface was carried out after the first 5 months of outdoor exposure and at the end of exposure 


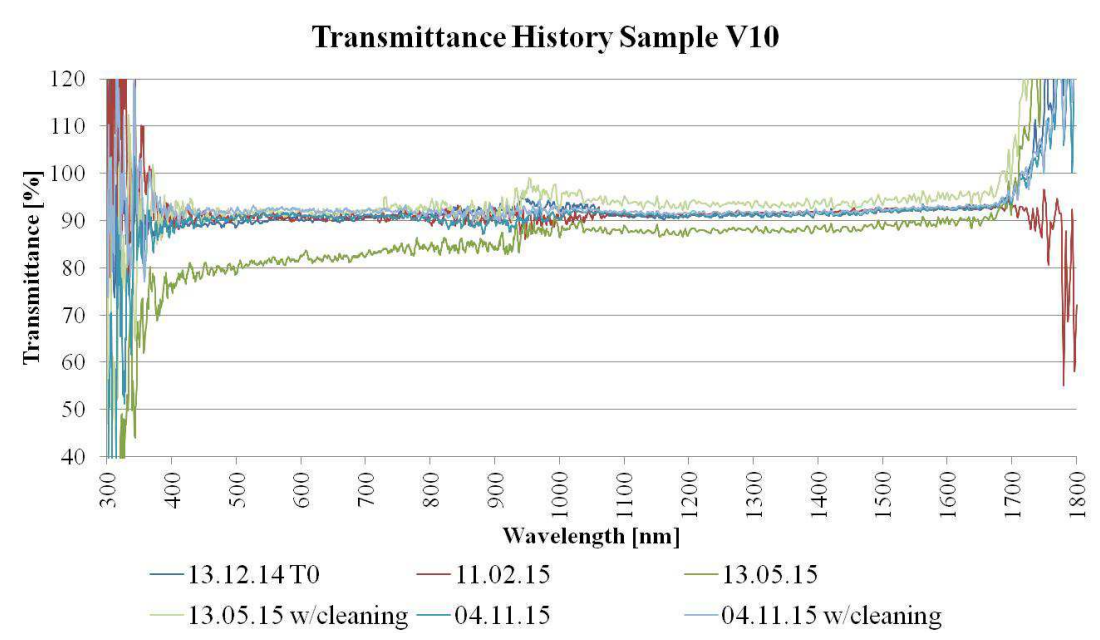

Fig. 13. Light transmittance monitoring of sample V10. Cleaning of the surface was carried out after the first 5 months of outdoor exposure and at the end of exposure

In the presented transmittance graphs, the first light transmittance reported is the one measured after the coating process, referred to as T0. As this issue is common for all the analyzed samples, it will not be discussed further in this study. Sample V01 was tilted at $20^{\circ}$ and the transmittance history analysis shows that it did not experience any decrease in transmittance between $\mathrm{T} 0$ and the measurement performed after 2 months of exposure. After additional 3 months of exposure the transmittance analysis reported a reduction around 3\% in the wavelength range between 450 and 750 $\mathrm{nm}$, while changes were negligible in the remaining part of the spectrum. As expected, surface cleaning increased light transmittance on the whole spectrum. An additional light transmittance measurement of light transmittance was performed at the end of test, both in soiled and cleaned condition. A difference in the spectrum after surface cleaning was encountered also in this case, but this latter being less significant than in the former case.

This may be ascribed to more frequent rain events during the last monitoring period, while measurements performed at 5 months exposure were recorded during the spring period, that is less rainy compared to fall season.

Sample V04 was tilted at $30^{\circ}$ and the transmittance history analysis shows that it did not experience any significant decrease in transmittance between $\mathrm{T} 0$ and the measurement performed after 2 months of exposure. After additional 3 months of exposure the transmittance analysis reported a reduction around $3 \%$ in the wavelength range between 450 and $750 \mathrm{~nm}$, which is even lower for the wavelengths closer to $750 \mathrm{~nm}$. In the remaining part of the spectrum the transmittance measured after 5 months of exposure was higher than the previous measurement. In this case, cleaning the sample increased the light transmittance for shorter wavelengths but did not produce significant changes in the portion of the spectrum above
$750 \mathrm{~nm}$. At the end of the experimental activity another measurement was recorded, both in the soiled and cleaned case. The spectrum was close to the original measurements for wavelengths below $1000 \mathrm{~nm}$ and lower for higher wavelengths. The behavior of sample V04 and V01 does not differ significantly, but the transmittance history analysis outlined the influence of a higher tilting angle to enhance self-cleaning effect over time.

Sample V09 was placed vertically and the difference with samples V01 and V04 is extremely evident. In this case the transmittance spectrum measured at different times is quite constant at all steps. As expected, cleaning increased the light transmittance in the whole spectrum but changes were not dramatic. This is due to the favorable inclination that intrinsically acts against dust deposition and enhances self-cleaning effectiveness in case of rain.

Sample V10 was placed horizontally and the difference between this sample and the previous three cases is immediately clear. In this case, transmittance decreased significantly in the whole spectrum after 5 months of outdoor exposure. No significant changes were reported after just two months of exposure proving beneficial effect of the coating. In fact, evidences from the literature state that the decrease in transmittance is usually more intense at the beginning of the outdoor exposure and then reduces its intensity until a saturation point (Appels et al., 2013). So, the application of Sol $\mathrm{T}$ coating has a beneficial effect in postponing dust and organic particles deposition and accumulation on the surface. The graph in Fig. 13 shows that transmittance dropped down by an average of $10 \%$ in most of the spectrum after 5-month exposure. As expected, cleaning brought the transmittance spectrum back to the original track, slightly increasing compared to the measurement at $\mathrm{T} 0$. 


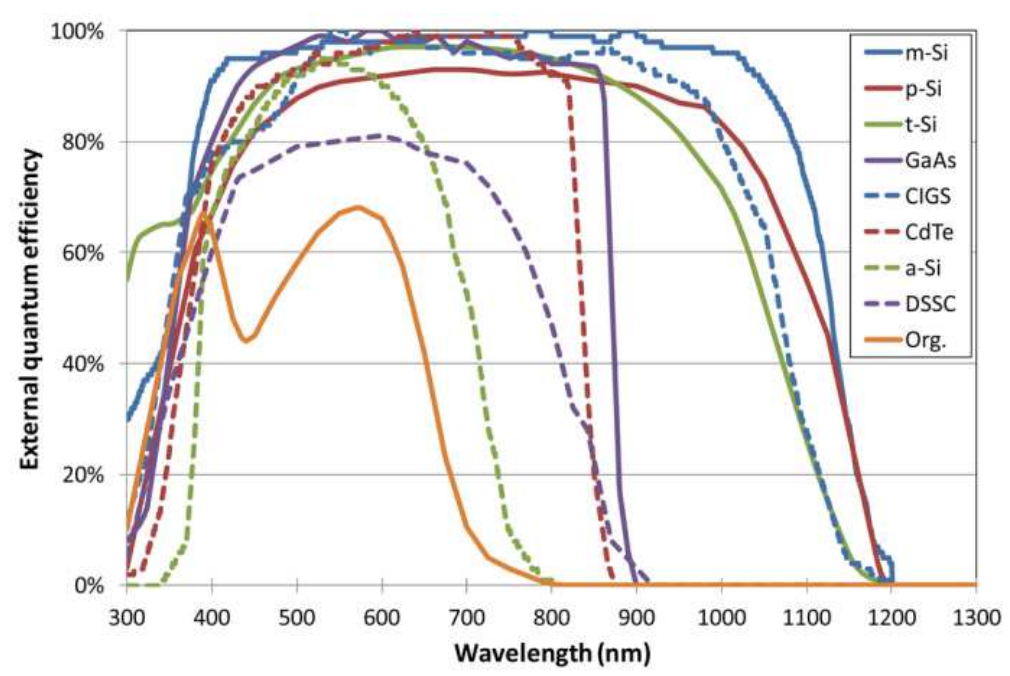

Fig. 14. External quantum efficiency of various PV technologies (Sarver et al., 2013)

The reported increased is ascribe to the lack of sample cleaning at the time of the first measurement. At the end of the monitoring period, light transmittance was measured again both in the soiled and cleaned conditions. In this case, the measurement was lower than what reported after 5 months of exposure, but the reduction in transmittance was less relevant than in the occasion of the previous measurement. As mentioned before, this difference may be supported by climate difference during the fall season (rainy) compared to the hot season.

Results from transmittance history show that in most of the cases soiling of the glass samples results in a light transmittance cut at the wavelength range between 400 and $900 \mathrm{~nm}$. The application of a selfcleaning coating, such as Sol $\mathrm{T}$, helps largely in limiting soiling related losses. This is quite relevant in the case of crystalline silicon PV cells, which present higher quantum efficiency at the wavelengths between 400 and $900 \mathrm{~nm}$ (Fig. 14).

So, self-cleaning coating application prevents or at least delays in time incident light transmission drop down at the most significant wavelengths for the photovoltaic system under test, where energy conversion rate is the highest.

\section{Conclusion}

The research work presented in this study had the aim of proving the use of self-cleaning coatings as a viable option for PV module maintenance. In fact, soiling related losses are among the main concerns for PV plants owners and managers, as they are responsible for extending the return time of investment in case of significant power production losses during service life. In addition, module soiling can also cause localized obstruction on the front glass which in turn can lead to precocious electrical decay. A variety set of experiments was developed to provide reliable evidence of selfcleaning coating efficiency on outdoor exposed modules and produced very promising results for the field of PV module maintenance.

The first part of research dealt with commercial monocristalline silicon photovoltaic modules that were treated with self-cleaning coatings and exposed outdoors for 12 months.

Module soiling was monitored through measurements of maximum power output in standard test conditions. Differences between the registered values for coated and non-coated modules show that the application of such coatings is able to prevent soiling deposition and build-up on the front glass surface. More specifically, coated modules have shown very reduced power losses due to soiling deposition after 12-month exposure. Conversely, the reference non-coated module showed significant losses directly related to soiling phenomena, higher than $2 \%$ of the nominal electric power. Experimental activities have proven that self-cleaning coating application can eliminate soiling related losses during the first year, allowing for consistent savings in terms of maintenance and operation of PV plants.

The second part of the research has been developed with the goal of evaluating electrical power output losses due to front glass soiling for different photovoltaic modules exposed according to various tilt angles. For the sake of completeness, both coated and uncoated modules were used also for this test. In addition, coated glass samples analogous to PV front glass were exposed to the same environment during the test period. This allowed to evaluate the reduction in light transmittance as an additional parameter to estimate the 
convenience of applying self-cleaning coatings. Soiling losses and self-cleaning activities were monitored indirectly through measurement of maximum power output in standard test conditions in the case of photovoltaic modules. Moreover, glass samples light transmittance was also monitored. To simulate maintenance actions, periodic cleaning of exposed modules and glass was scheduled.

Results from the test showed that the presence of self-cleaning coated glass delays significantly dust and soil build-up on the glass surface. As far as different tilt angles are concerned, it is possible to state that $20^{\circ}$ and $30^{\circ}$ inclinations present quite similar soiling patterns. However, the presence of self-cleaning coatings on PV modules enhances the natural cleaning effect under the action of rainfall in the case of more sloped surfaces. Vertical modules did not show consistent variations between coated or uncoated surfaces and similar considerations also apply to horizontal surfaces, even if in this latter case the presence of a self-cleaning coating may have slightly delayed soiling depositing and stratification in time. Dry seasons are of course less favorable with regards to surface self-cleaning under the effect of driving rain. In addition, periodic cleaning on uncoated surfaces is another alternative to keep performance levels close to the original ones over time. However, these operations need to be repeated frequently, namely every two or three months to ensure that no significant variation in electric power output takes place. This fact makes the alternative of manual washing not very sustainable under the environmental and economic points of view. To add to this, test have shown that even thorough cleaning operations may sometimes not guarantee the achievement of initial performance levels. In the case of this test, washing was carried out using simple water and a clean cloth to wipe away residual drops and in several cases this has not been enough to restore original performance values. This is a notable observation, as maintenance and operation costs on extensive PV plants should be kept as low as possible and it is reasonable to assume that cleaning operations are usually performed in such a basic fashion.

Experimental activities demonstrated that the application of titanium dioxide nanotechnological coatings on PV module is able to prevent stable soiling deposition on active surfaces, where the presence of such deposits can cause performance decrease and precocious technical malfunctioning, in addition to aesthetic concerns that are equally affecting all kind of exposed surfaces.

The topic of PV maintenance and cleaning has acquired increasing importance over the years, as soiling related losses are responsible for causing economic losses to plant owners with respect to the initial design expected power output. Such concerns are also due to the sustainability trend of the contemporary society, which plays against manually performed cleaning operations that usually turn out to be costly and resource consuming. This is also among the main reasons for the integration of functional and smart materials in the field of PV maintenance.

The relevance of this research work lays in the positive results of the extensive experimental campaign, which had been set-up and carried out with the specific objective of proving titanium dioxide efficiency and compatibility with PV systems. Finding of this work are encouraging and should foster an increase in self-cleaning coating integration when designing new PV plants, in addition to considering its retrofit application on existing plants and building integrated photovoltaics.

\section{Acknowledgement}

The authors sincerely acknowledge Nextmaterials s.r.l. for sponsoring the research project through unlimited supply of the Sol T self-cleaning product. In addition, authors gratefully thank colleagues at the PV Area, Swiss PV Module Test Centre of SUPSI for providing help in the set-up of experimental activities and experienced guidance in test performing.

\section{Funding Information}

This research was carried out within the frame of a doctoral project funded by the Italian Ministry of Education, University and Research (Dottorato XXVIII ciclo at Politecnico di Milano) and in collaboration with SUPSI.

\section{Author's Contributions}

Author's contribution in the development of this manuscript can be summarized as follows:

Annalisa Andaloro: Design of the work, data collection, data analysis and interpretation, drafting the article, Critical revision of the article and final approval of the version to be published.

Francesco Frontini: Design of the work, Critical revision of the article and final approval of the version to be published.

\section{Ethics}

Authors declare that there are no ethical issues they presently aware of, which may arise from publication of this work. 


\section{References}

Andaloro, A., 2016. Self-cleaning as a sustainable alternative to envelope maintenance. Study of functional materia applications to the building envelope. Doctoral dissertation, Politecnico di Milano.

Appels, R., B. Lefevre, B. Herteleer, H. Goverde and A. Beerten et al., 2013. Effect of soiling on photovoltaic modules. Solar Energy, 96: 283-291. DOI: 10.1016/j.solener.2013.07.017

Beattie, N.S., R.S. Moir, C. Chacko, G. Buffoni and S.H. Roberts et al., 2012. Understanding the effects of sand and dust accumulation on photovoltaic modules. Renewable Energy, 48: 448-452. DOI: 10.1016/j.renene.2012.06.007

Diamanti, M.V., B. Del Curto, M. Ormellese and M.P. Pedeferri, 2013. Photocatalytic and self-cleaning activity of colored mortars containing $\mathrm{TiO}_{2}$. Constr. Build. Mater., 46: 167-174.

DOI: $10.1016 /$ j.conbuildmat.2013.04.038

Dorobantu, L., M.O. Popescu, C.L. Popescu and A. Craciunescu, 2011. The effect of surface impurities on photovoltaic panels. Proceedings of the International Conference on Renewable Energies and Power Quality, Apr. 13-15, Las Palmas de Gran Canaria (Spain), pp: 622-626.

Jiang, H., L. Lu and K. Sun, 2011. Experimental investigation of the impact of airborne dust deposition on the performance of solar photovoltaic (PV) modules. Atmospheric Environ., 45: 4299-4304. DOI: 10.1016/j.atmosenv.2011.04.084

Kaldellis, J.K. and M. Kapsali, 2011. Simulating the dust effect on the energy performance of photovoltaic generators based on experimental measurements. Energy, 36: 5154-5161.

DOI: $10.1016 /$ j.energy.2011.06.018

Kaldellis, J.K. and A. Kokala, 2010. Quantifying the decrease of the photovoltaic panels' energy yield due to phenomena of natural air pollution disposal. Energy, 35: 4862-4869.

DOI: $10.1016 /$ j.energy.2010.09.002

Kalogirou, S.A., R. Agathokleous and G. Panayiotou, 2013. On-site PV characterization and the effect of soiling on their performance. Energy, 51: 439-446. DOI: 10.1016/j.energy.2012.12.018

Kimber, A., L. Mitchell, S. Nogradi and H. Wenger, 2007. The effect of soiling on large gridconnected photovoltaic systems in California and the Southwest Region of the United States. Proceedings of the IEEE 4th World Conference on Photovoltaic Energy Conversion, May 7-12, IEEE Xplore Press, pp: 2391-2395.

DOI: 10.1109/WCPEC.2006.279690
Lorenz, T., E. Klimm and K.A. Weiss, 2013. Soiling and anti-soiling coatings on surfaces of solar thermal systems-featuring an economic feasibility analysis. Energy Proc., 48: 749-756. DOI: $10.1016 /$ j.egypro.2014.02.087

Mejia, F.A. and J. Kleissl, 2013. Soiling losses for solar photovoltaic systems in California. Solar Energy, 95: 357-363. DOI: 10.1016/j.solener.2013.06.028

Mekhilef, S., R. Saidur and M. Kamalisarvestani, 2012. Effect of dust, humidity and air velocity on efficiency of photovoltaic cells. Renewable Sustainable Energy Rev., 16: 2920-2925.

DOI: 10.1016/j.rser.2012.02.012

Rao, A., R. Pillai, M. Mani and P. Ramamurthy, 2014. Influence of dust deposition on photovoltaic panel performance. Energy Proc., 54: 690-700. DOI: 10.1016/j.egypro.2014.07.310

Rocha, M.P., J.E.C. Rubio, M. Sidrach-de-Cardona, D. Montiel and P. Sánchez-Friera et al., 2008. Comparative analysis of the dust losses in photovoltaic modules with different cover glasses. Proceedings of the 23rd European Photovoltaic Solar Energy Conference, Sept. 1-5, Valencia, Spain, pp: 2698-2700. DOI: 10.4229/23rdEUPVSEC2008-4CO.1.2

Sarver, T., A. Al-Qaraghuli and L.L. Kazmerski, 2013. A comprehensive review of the impact of dust on the use of solar energy: History, investigations, results, literature and mitigation approaches. Renewable Sustainable Energy Rev., 22: 698-733. DOI: $10.1016 /$ j.rser.2012.12.065

Sayyah, A., M.N. Horenstein and M.K. Mazumder, 2014. Energy yield loss caused by dust deposition on photovoltaic panels. Solar Energy, 107: 576-604. DOI: 10.1016/j.solener.2014.05.030

Zang, J. and Y. Wang, 2011. Analysis of computation model of particle deposition on transmittance for photovoltaic panels. Energy Proc., 12: 554-559. DOI: 10.1016/j.egypro.2011.10.075

Zorrilla-Casanova, J., M. Piliougine, J. Carretero, P. Bernaola and P. Carpena et al., 2011. Analysis of dust losses in photovoltaic modules. Proceedings of the World Renewable Energy Congress, May 8-13, University de Málaga, Spain, pp: 2985-2992. DOI: $10.3384 /$ ecp1 10572985 